\title{
Building a Bridge Between Authentic Learning and Service Learning: A Case Study From an English Technical Writing Class
}

\author{
Yingqin Liu \\ Cameron University, Lawton, USA
}

\begin{abstract}
In order to help technical/business writing students transfer their authentic learning experience to service learning practice, this study explores the relationship between authentic learning and service learning through a course research project at a small public university in southwestern Oklahoma, USA. The participants, a small group of technical writing students, engaged in writing a proposal targeting a real-life local problem as well as finding a solution. The study shows that authentic learning, such as writing the proposal for a real-world problem, can generate a potential solution while the service learning portion of the assignment (such as working with the community) can provide a specific real-life location for resolving the problem. The study also shows that the authentic learning experience can inspire the students to move further to serve the community and when students volunteer to help the local community implement the solution, a bridge between the authentic learning and service learning can be built, which can then lead to students' enhancement of all round real-life skills and of a sense of serving the community. Finally, the implications of the study for English language teaching in an authentic learning context also will be discussed.
\end{abstract}

Keywords: authentic learning, service learning, transformative learning, business proposal, community

\section{Introduction}

Authentic learning, according to Sven B. Andersson and Ingrid Andersson (2005), seeks to increase students' motivation and learning by creating genuine connections to material by relating it to the real world. It considers students' perspectives and adapts the learning content to make it meaningful and genuine to the learners through tasks associated with real-life situations. The advantages of using authentic learning in the classroom have been seen by many educators through their first-hand experiencing with authentic learning strategies in their classrooms. Ma and Lee (2012) suggest that there are three benefits to authentic learning. First, it can increase students' communication skills through teamwork interaction. Second, it can enhance students' research skills since they need to gather relevant information for their class topic beyond their class sessions. Finally, it can improve students' understanding of course content through applying book knowledge to real-world usage.

Service learning, "a method under which students or participants learn and develop through active participation in thoughtfully organized service” (Billig, 2000, p. 659), on the other hand, possesses the above

Yingqin Liu, associate professor, Ph.D., Department of English and Foreign Languages, Cameron University. 
strengths of authentic learning. However, it presents its own unique advantages in promoting students' education. One important advantage is that service learning may function as "a form of experiential learning that calls on students to use their academic knowledge and skills to benefit them as well as the community" (George, 2004, p. 37). Another unique benefit is that service learning can lead to "transformative learning" (Cranton, 2006; Mezirow, 2000). In other words, it challenges the traditional student identities and roles. It urges them not only to consume knowledge but also to produce it (Feltern \& Clayton, 2011) when they collaborate with the community they serve. Thus, service learning can provide students with what Eyler and Giles (1999) call a "new set of lenses for seeing the world" (p. 129) and new ways of being in it since the learners change their frame of reference by critically reflecting on their assumptions, beliefs, and understanding of the world (Feltern \& Clayton, 2011).

It is obvious that, while both authentic learning and service learning allow students to explore, discuss, and meaningfully construct concepts and relationships in contexts that involve real-world problems, the two learning experiences do offer different advantages. First, the foci of the authentic learning and service learning are different. The former emphasizes the context directly related to students' professional careers, but the latter focuses on the context relevant to a community project that may not necessarily be closely related to students' professional career (Ma \& Lee, 2012). Second, in authentic learning, the students' goal is to apply knowledge learned in the classroom to solve real-world problems, whereas in service learning, students aim at both promoting their education and serving the community. Therefore, if the educators can find ways to connect these two types of learning for students, they might help to enhance students' all round real-life skills in real-world settings and improve the quality of their education. However, there does not exist much research on studying the possible transformation of an authentic learning project into a service learning project.

The purpose of this study is to explore how English technical writing teachers might help build a bridge between authentic learning and service learning. The study will focus on reporting and analyzing a case study in which one English technical writing student group went through a successful learning experience of transforming their authentic learning experience into a service learning project. The study will address the following research questions:

(1) How can technical writing teachers help generate opportunities for technical writing students to not only gain authentic learning experience but also service learning practice through a course project?

(2) What can motivate the students to further transform the outcome of the authentic learning to service learning?

(3) What might be the relationship between authentic learning and service learning reflected in this technical writing course project?

\section{Methodology}

\section{Participants and Settings}

One group of three students from an Introductory Technical Writing class (English 2333) offered at a small public university in southwestern Oklahoma during the Spring 2013 semester participated in this study. Two of the students took the class as a requirement for their major while the other student took the course as an elective.

The participants were given one month's time to engage in writing a group research proposal. Here are the proposal assignment descriptions (written by the researcher) used in the study: 
For this assignment, your group will work on writing a planning proposal: You are required to do some preliminary or primary research to demonstrate your grasp of a real LOCAL problem such as one existing on our campus, in your work place, or in your community, in order to offer a solution to resolve it. The focus of your planning proposal is on convincing the audience that you can offer the best, most relevant and comprehensive plan or solution(s) to address/solve the identified problem.

Your proposal should be fairly detailed (6-8 single-spaced pages in block paragraph format). Your proposal should include a mixture of primary and secondary research.

(1) The secondary research should mostly serve to frame the issue such as in a literature review for the problem and solutions you are discussing.

(2) The primary research should be focused on gathering the first-hand information that helps you fill the gap in understanding and demonstrating the problem you have identified and evaluate your solution(s).

At the very beginning, each group member will submit a Proposal Topic-Idea Work Sheet to show your initial contribution to your group proposal project.

In the middle of your project,

(1) Your entire group will finish and submit a memo-of-progress report about your group project.

(2) At the time of submitting the progress report, your group is required to have finished more than two thirds of your group proposal.

(3) The group leader reserves the right to request each group member provide him or her with an individual progress report on the member's assigned individual tasks before the group memo of the progress report will be due.

At the end of the project, from an individual perspective, each group member will also submit

(1) a Team-Member Evaluation Form to show how each member works within the group project and

(2) a Self-Evaluation Form to record and reflect your own participation in this group project.

The above assignment descriptions display three main characteristics that any authentic learning assignment entails: a real-life project, interaction among group members, and reflection on the individual learning experience (Stein, Isaacs, \& Andrew, 2004).

First, this proposal project is a real-world project: It provides students with opportunities for authentic learning because they must identify a real local problem such as one existing on their campus, in their workplace, or in their community, in order to offer a solution. To accomplish this first task of recognizing a real problem, the students needed to conduct primary research via doing surveys, interviews, or focus group discussions. They needed to go to real locations such as classrooms, faculty offices, school libraries, or workplaces, and talk with fellow students, faculty, coworkers, or people in their community to obtain the first-hand knowledge of the problem they chose. For example, in the proposal covered in this paper, the three student participants identified a serious local problem in their community (litter in the Wichita Mountain Wildlife Refuge, a National Park). They stated,

Every year there are over 1.5 million visitors to the Refuge. When visitors enter into the habitat and homes of this area's wildlife, often they leave more behind than just their footprints. Glass, bags, bottles, fishing hooks and other debris pose a threat to the animals and the environment. Litter is becoming an all too common sight in this natural environment. Any amount of litter is unhealthy to both wildlife and tourists alike... (Poolaw \& Johnson, 2014)

Of course, before they could describe anything about the problem, they had to investigate the site of the Wichita Mountain Wildlife Refuge many times and interact with visitors and workers there for first-hand knowledge and an understanding of the problem.

Another key feature of authentic learning the proposal project reflects is that of group interaction. For this research proposal, except for the instructor's providing basic information about proposals, the student participants had to meet regularly to discuss the readings, analyze the data, and collaborate in writing different 
sections of the proposal project such as solution(s) to the problem, cost and schedule(s). Thus, as Stein et al. (2004, p. 249) argued, this group work provided the participants with chances to wrestle with book knowledge and frameworks of understanding, to analyze and critique, and to synthesize ideas to make them their own. But most important, this process shows that the student participants could interact with the ideas that are authentic, realistic, and workable to the identified problems. Additionally, the group interaction also allowed the participants to learn how to manage their own time to meet deadlines such as finishing their proposal progress report and presenting their group proposal to the rest of their class. In this way, they were given the opportunities to take charge of their own learning while learning from one another to compensate for what a particular individual might lack.

Finally, the proposal project also requests that students reflect on their learning experiences through self-evaluation writing and writing team member evaluations. In these activities, students not only reviewed their peers' participation but also discussed what they thought they did well in the proposal project and what each believed he or she needed to improve in a future task. Engaging in these reflections helped the participants to bring the theory and practice together and learn from their own experiences.

\section{Procedures}

The data for this case study was gathered over two separate periods. The first period lasted a month during which the student participants worked on and finished their research proposal projects during the spring semester of 2013. The second period started in the middle of August, 2013 and finished at the end of September 2013, during which the student participants had their proposal accepted by the organization involved and implemented solutions. Finally, a follow-up e-mail inquiry was conducted by the researcher at the end of the case study.

\section{Findings and Discussion}

The findings of the case study will be reported and analyzed in the form of answering the three research questions for this study:

(1) How can technical writing teachers help to generate opportunities for technical writing students to not only gain authentic learning experience but also service learning practice through a course project?

In this study, using local problems with authentic solutions created an authentic learning context for the students. The proposal submitted by the student participants is a good example to illustrate this authentic learning experience.

In their proposal, the participants identified a problem at the Wichita Mountain Wildlife Refuge. They further described the problem in their proposal,

The reserve spans over 59,020 acres of granite mountains, mixed grass prairie and remnant cross-timbers. It is home to over 800 species of plants, animals and insects. At any given time, there are approximately 30 employees of the WMWR. Every year there are over 1.5 million visitors to the Refuge. When visitors enter into the habitat and homes of this area's wildlife, often they leave more behind than just their footprints. Glass, bags, bottles, fishing hooks and other debris pose a threat to the animals and the environment. Litter is becoming an all too common sight in this natural environment. Any amount of litter is unhealthy to both wildlife and tourists alike. While we believe that the refuge has done an amazing job for generations at caring for wildlife, we seek to improve the overall habitat of refuge by cleaning up what others have left behind and fixing what has been damaged. (Poolaw \& Johnson, 2014)

During their one month's research period, they conducted their own primary research to examine the 
problem and propose solutions to resolve it. For example, during their on-site observations, they visited the Refuge a total of five times, during which they made a conscious effort to document any litter that they observed in a variety of locations. They also performed a survey with a cross-section of students at the university with the intent of enlisting potential volunteers from the survey sample. In order to get support from the local organization, they interviewed one officer of the Wichita Mountain Wildlife Refuge, who actually became their point of contact on the Refuge. They stated that his knowledge on the issue was important in their research, and he enlightened them the negative effects that different types of litter can have on the wildlife and the demanding issues associated with the addition of more waste receptacles.

With all their research data collected and analyzed, the participants came to some possible solutions. One was to raise public awareness of protecting the Refuge by avoiding littering. They wrote, "At every opportunity, visitors should be reminded that this 'harmless' act can actually kill or damage wildlife and their environment" (Poolaw \& Johnson, 2014). Another was to use stricter penalties to punish those who are caught littering on the Refuge. They recommended that the District Federal Court allow for fines between $\$ 200$ and $\$ 5000$, community service, imprisonment and/or a misdemeanor charge for anyone caught littering. Presently, the Refuge currently cites those who are caught littering \$125 (Poolaw \& Johnson, 2014). Finally, the participants suggested that the Refuge utilize volunteers in litter relief efforts when adding more employees is not possible (Poolaw \& Johnson, 2014). To help the Refuge with this last solution, the student participants recommended a specific way to incorporate the volunteers' effort: two clean-up days a year to be dedicated to the Wildlife Refuge. The first day would be National Public Lands Day in September and the second would be on National Pick-Up Day in April (Poolaw \& Johnson, 2014).

It is clear that the whole research process of writing the proposal immersed the students in a real-world authentic learning experience. However, even though the finished proposal by the student participants helped the Refuge with possible solutions to the littering crisis, what the student participants accomplished at this stage still mainly focused on what Mueller (2008) suggests in drawing upon students' talents and experiences in real-world tasks that demonstrate meaningful applications of essential knowledge and skills from the classroom. Undoubtedly, in this case study, the student participants had learned how to incorporate the book knowledge of writing a proposal for a real-world problem, the Refuge litter crisis through authentic learning. In other words, the student participants had benefited from this learning experience but not the Refuge yet, since the proposed solutions had not been put into practice. Also, the students had not experienced the personal growth described by Cooper (2013, p. 294) that would result from sharing a common interest interaction with the coworkers in the community and from gleaning the benefits of their co-workers' experience and ideally contribute to the learning of their co-workers, as well from service learning.

So, as educators, technical writing teachers need to make efforts to fill this gap between authentic learning and service learning and help students to move beyond authentic learning and obtain some service learning experiences. In this case study, what the instructor/researcher did to bridge the gap was to advise the students to revisit the Refuge and offer their solutions to the litter problem and try to persuade them to accept their proposal. The instructor/researcher also encouraged the students to prepare a research proposal for an annual state conference presentation for undergraduate students in March 2014.

The student participants responded to the encouragements very enthusiastically. After the class was over at the end of the spring semester of 2013, they continued their research project, made several more field trips to the Refuge, and had their proposal accepted by the Refuge. They started to engage in additional service 
learning activities for the Refuge such as raising funds, advertising, and recruiting volunteers for the big cleaning events proposed in the proposal. On September 29, 2014, they helped the Refuge organize the first cleaning event with more than 100 volunteer participants from the local community.

(2) What can motivate the students to further transform the outcome of the authentic learning to service learning?

The students' genuine interest in and care for helping the community and their organizing ability and devotion to the service learning project played a key role in further transforming the authentic learning experience to service learning experience in this case study. As one student participant wrote,

I choose the topic because it was something that I was genuinely interested in. I believed that this solution could be implemented to help. Once I dove into the project and began conducting interviews and outlining a plan of action, I became very passionate about it very quickly. The support that I was met with was encouraging. It is inspirational to see people who share similar interest. (Student 2, personal communication, September 9, 2013)

(3) What might be the relationship between authentic learning and service learning reflected in this technical writing course project?

This case study indicates that there is a close connection between authentic learning and service learning. While authentic learning such as the proposal with a real local problem provided potential solutions, the service learning offered a specific real-world place to implement the solution(s). The service learning experience also provided the participants the opportunities to test the effectiveness of their solutions. It helped the participants see the connection between authentic learning and service learning in this specific learning context. Additionally, the e-mail inquiry with the student participants reveals that authentic learning experience can arouse the students' interest in and concerns about the problem and raise their sense of responsibility for the community and their awareness that they can help improve a problematic situation. The authentic learning experience such as the proposal project can also prepare the students to move further in improving the situation through getting the proposal accepted. Finally, when students volunteered to help resolve the problem through participating in more community activities, the bridge between the authentic learning and the service learning could be built.

\section{Limitations of the Study}

The case study has some limitations that could restrict the "generalizability" of the study due to the small sample size and the specific nature of the service learning project. Future study might consider using more participants and a variety of authentic learning and service learning projects to further explore the relationship between the two.

\section{Conclusion and Implications}

The findings of the case study demonstrate that transforming authentic learning to service learning can further help bring the real-world into the classroom and make the classroom culture reflect the real-world culture more realistically. That is to say that English technical writing teachers can use education (in this case, a technical writing class) as a medium for changes that better our community. One student participant (see the Appendix) stated that

I have learned how problems are solved through writing a proposal and conducting a service project. I now see how technical writing can be used to benefit the community. Technical writing is a necessary precursor for action to take place. 
(Student 1, personal communication, September 6, 2013)

The case study also shows that when students had some agency over their learning, they would participate more actively because the content was made meaningful by relating it to lived practice. This helps explain why the students were motivated in transforming their research project into the service learning project. The study also supports the assumption that through engaging in service learning projects, students' motivational level can increase because they feel more personally related to class content through community-based projects and become more aware of the importance of learning in the social context than when they are taught using a traditional classroom teaching method (Kahan, 1998; LaMaster, 2001). In fact, this implication of providing students with some agency over their learning can offer some insights beyond pedagogy of English technical writing; it also is applicable for any traditional classroom teaching setting. For example, the researcher, who also taught English for academic purpose classes and followed this approach of creating more meaningful educational contexts related to students, engaged her English language learning students in writing reading reflections focusing on cultural topics that were related to each student's ethnical and cultural background. It turned out that these English language learners were very enthusiastic about reflecting on what they had read because they found that they could relate the readings with their own life experience; thus, they had more things to discuss and share in their reading reflections. As a result, this self-motivated writing practice also helped the students improve their English essay writing. Certainly, English language teachers can create more opportunities in providing English language learners with realistic and meaningful learning contexts in any other language courses to promote their English learning and teaching. Hopefully, English language teachers might also consider incorporating some service learning elements into their English language teaching classrooms, thus encouraging English language students to use what they have learned from their English classes to serve their communities.

Finally, just as Sedlak, Dogeny, Panthofer, and Anaya (2003) point out, a service learning project can help students develop personal and professional plans as well as life values. One student participant (see the Appendix) stated that

I feel like I've learned many things through this experience. I've learned how to conduct interviews. I've experienced the stress of having to plan and organize an event. I have had to overcome setbacks in soliciting donations and volunteers. I have organized a proposal and presented effectively. I feel like this has given me a very accurate representation of the career field I could potentially be entering. (Student 1, personal communication, September 6, 2013)

Therefore, it seems safe to say that English technical writing teachers can help build a bridge between authentic learning and service learning through their course projects can provide opportunities for their students to explore new ideas for themselves.

\section{References}

Andersson, S. B., \& Andersson, I. (2005). Authentic learning in a sociocultural framework. Scandinavian Journal of Educational Research, 49(4), 419-436.

Billig, S. (2000). Research on K-12 school-based service-learning: The evidence builds. Phi Delta Kappan, 81(9), 658-664.

Cooper, L. Z. (2013). Student reflections on an LIS internship from a service learning perspective supporting multiple learning theories. Journal of Education for Library and Information Science, 54(4), 286-298.

Cranton, P. (2006). Fostering authentic relationships in the transformative classroom. New Directions for Adult and Continuing Education, 109, 5-13.

Eyler, J., \& Giles, D. E. Jr. (1999). Where’s the learning in service-learning?. San Francisco: Jossey-Bass. 
Feltern, P., \& Clayton, P. H. (2011). Service-learning. New Direction for Teaching and Learning, 10, 75-84.

George, P. (2004). Service learning: Putting knowledge to work. Middle Ground, 8(2), 35-40.

Kahan, D. (1998). When everyone gets what they want. Action in Teacher Education, 18, 43-60.

LaMaster, K. J. (2001). Enhancing preservice teachers filed experiences through the addition of a service-learning component. Journal of Experiential Education, 24, 27-33.

Ma, Y. J., \& Lee, H. H. (2012). Incorporating an authentic learning strategy into undergraduate apparel and merchandising curriculum. Journal of Experiential Education, 35(1), 272-289.

Mezirow, J. (2000). Learning as transformation: Critical perspectives on a theory in progress. San Francisco: Jossey-Bass.

Mueller, J. (2008). What is authentic assessment? Retrieved from http://jonathan.muller. faculty.noctrl.edu/meridian/win2003/

Poolaw, R., \& Johnson, K. (2014, March). Wichita mountain wildlife refuge clean-up. Student poster session presented at Oklahoma Research Day, Almond, OK, USA.

Sedlak, C. A., Dogeny, M. O., Panthofer, N., \& Anaya, E. (2003). Critical thinking in student's service learning experiences. College Teaching, 51(3), 99-103.

Stein, S. J., Isaacs, G., \& Andrew, T. (2004). Incorporating authentic learning experiences within a university course. Studies in High Education, 29(2), 239-258.

\section{Appendix: The Follow-up E-mail Inquiry Questions}

What motivated you to continue this proposal even when class was over?

In what ways, do you feel this learning experience is useful to your educational experience?

What are the most challenging things you have to face during conducting this project?

What is the most useful knowledge you obtained from conducting this project?

In what ways, this proposal and service project have helped you to understand the functions of technical writing? 